\title{
Peripheral Odor Coding in the Rat and Frog: Quality and Intensity Specification
}

\author{
Patricia Duchamp-Viret, André Duchamp, and Michel A. Chaput \\ Laboratoire de Neurosciences et Systèmes Sensoriels, Unité Mixte de Recherche, Centre National de la Recherche \\ Scientifique-Université Claude Bernard Lyon 1, 69622 Villeurbanne cedex, France
}

In mammals, two recent studies have shown recently that one odor molecule can be recognized by several molecular olfactory receptors (ORs), and a single OR can recognize multiple odor molecules. In addition, one olfactory receptor neuron (ORN) may respond to different stimuli chosen as representative of distinct odor qualities. The aim of the present study was to analyze quality and intensity coding abilities of rat single ORNs, comparing them with previous extensive data gathered in the frog to get insight into the generality of olfactory coding mechanisms over vertebrates.

Response properties of 90 rat ORNs to different odors or to one odor at different concentrations were analyzed. In the rat and the frog, odor quality appears to be specified through the identity of activated ORNs.
However, rat ORNs have higher response thresholds. This lower sensitivity may be interpreted as an increase in selectivity of rat ORNs for low or medium odor intensities. In these conditions, the lower proportion of activated ORNs could be counterbalanced by their number, as well as by their higher glomerular convergence ratio in the olfactory bulb. From amphibians to mammals, the olfactory system appears to use universal mechanisms based on a combinatorial-coding mode that may allow quasi-infinite possibilities of adaptation to various olfactory environments.

Key words: olfaction; odor; rat olfactory receptor neurons; odor coding; in vivo single-unit extracellular recordings; comparison between amphibian and mammalian olfactory receptor response properties
The identification of a novel multigene family that appears to encode proteins with seven transmembrane domains that may bind odor molecules and transduce odor reception signal through interactions with G-proteins (Buck and Axel, 1991; Buck, 1993; Raming et al., 1993) constitutes a major contribution of molecular biology to odor transduction issue. It shed new light on the question of odor coding and gave rise to a way of thinking that places the interaction between odor molecules and their olfactory molecular receptors (ORs) at the center of transduction mechanisms.

In mammals, our knowledge of the degree of specificity of odor-receptor interaction mechanisms has been enriched recently by two functional studies that differ by their methodology but are complementary in the information they provide. The first one is the calcium-imaging study coupled with reverse transcription-PCR of rat olfactory receptor neurons (ORNs) in vitro (Malnic et al., 1999) in which the authors conclude that ORNs express only one OR each but suggest that odor-receptor interactions can be realized through multiple combinations. Thus, one odor molecule will be recognized by several ORs, while one OR will be able to bind multiple odor molecules. The second one is our electrophysiological study performed in the rat in vivo (Duchamp-Viret et al., 1999) that shows that one ORN may respond to different stimuli chosen as representative of distinct

\footnotetext{
Received Sept. 27, 1999; revised Dec. 28, 1999; accepted Dec. 28, 1999.

We are grateful to Dr. G. Sicard for the mathematical analyses of the data and Dr. J. W. Scott for his comments on this manuscript.

Correspondence should be addressed to P. Duchamp-Viret, Laboratoire de Neurosciences et Systèmes Sensoriels, Unité Mixte de Recherche, Centre National de la Recherche Scientifique-Université Claude Bernard Lyon 1, 43 boulevard du 11 novembre 1918, 69622 Villeurbanne cedex, France. E-mail: pduchamp@olfac.univlyon1.fr.

Copyright (C) 2000 Society for Neuroscience $\quad 0270-6474 / 00 / 202383-08 \$ 15.00 / 0$
}

odor qualities. Based on the hypothesis that one ORN would be endowed with one OR, this study argues in favor of a broad odor-quality tuning of ORs.

In light of these observations, the concept of combinatorial peripheral coding, initially named "across fiber pattern" (Erickson, 1963), becomes topical again. This type of coding, which involves numerous ORs and ORNs to specify one odor quality, would produce a very enriched code. As a matter of fact, a code based on a quasi-infinity of cell combinations can both allow specification of pure chemicals with close molecular structures through a continuum of variation of cell responses and generate highly distinct patterns for complex odor mixtures.

This report sought to further document the rules governing odor-receptor interactions at the level of single ORNs. Because the qualitative and quantitative coding abilities of ORNs have been extensively analyzed in the frog (Duchamp et al., 1974; Revial et al., 1978a,b, 1982, 1983; Sicard and Holley, 1984), comparing these previous studies with data gathered in the rat should provide insight into the generality of olfactory coding mechanisms. To analyze the olfactory coding abilities of ORNs, series of responses of ORNs to different odors or to one odor at different concentrations were obtained. This paper opens the useful opportunity to discuss our data with respect to those obtained recently by Malnic et al. (1999) through molecular and calcium imaging and attempts to get insight on some rules governing the interactions between molecular odor receptors and multiple odorants.

\section{MATERIALS AND METHODS}

Surgical methods. Experiments were performed in accordance with the European Communities Council Directive for the care and use of laboratory animals. Adult Wistar rats $(n=35$; weight, $250-300 \mathrm{gm})$ were anesthetized by an intraperitoneal injection of Equithesine (mixture of 
pentobarbital sodium and chloral hydrate) at the initial dose of $3 \mathrm{ml} / \mathrm{kg}$ and were secured in a stereotaxic apparatus for surgical preparation. Anesthetic was then supplemented as necessary to maintain a deep level of anesthesia. Rectal temperature was maintained at $37 \pm 0.5^{\circ} \mathrm{C}$ by a homeothermic blanket (Harvard Apparatus, Holliston, MA), and surgical wounds of the animals were regularly infiltrated with $2 \%$ Procaine.

Odor stimuli. Sixteen pure odor compounds were used as stimuli in this study: acetophenone (ACE), anisole (ANI), camphor (CAM), cineole (CIN), cyclodecanone (CDN), cyclohexanone (HEX), p-cymene (CYM), heptanol (HEP), limonene (LIM), iso-amyl acetate (ISO), methyl-amyl ketone (MAK), vanillin (VAN), and two pairs of enantiomers, $l$ - and $d$-carvone ( $l$ - and $d$-CAR) and $l$ - and $d$-citronellol ( $l$ - and $d$-CIT). They were selected for their effectiveness, their molecular structure, and their previous use in the frog (Duchamp-Viret and Duchamp, 1997). Some of them were clearly established as members of qualitative groups through studies of Duchamp, Revial, and collaborators (Duchamp et al., 1974; Revial et al., 1978a,b, 1982, 1983; Sicard and Holley, 1984). CAM and CIN belong to the camphor group, LIM and CYM belong to the terpene group, ACE and ANI belong to the aromatic group, MAK and ISO are linear ketones, and CDN and HEX are cyclic ketones. Only VAN had never been tested in the frog in vivo. It was chosen to get information on the $\mathrm{IP}_{3}$ transduction pathway (Sklar et al., 1986).

Stimuli consisted of odor pulses of $2 \mathrm{sec}$ duration delivered at 200 $\mathrm{ml} / \mathrm{min}$. They were applied directly near the surface of the turbinate using a dynamic multistage olfactometer as described previously (Vigouroux et al., 1988), which ensured a precise control of the concentration range and allowed the delivery of 12 discrete concentrations. Depending on their saturated vapor pressure (SV), compounds were delivered at concentrations ranging from $2.5 \times 10^{-8} / 5.2 \times 10^{-7} \mathrm{M} / 1$ $(\mathrm{SV} / 562)$ to $1.4 \times 10^{-5} / 2.9 \times 10^{-4} \mathrm{M} / 1(\mathrm{SV})$. Stimuli were delivered from the lowest to the highest concentration, and a delay of at least $2 \mathrm{~min}$ elapsed between successive odor presentations.

Electrophysiological recordings and experimental paradigm. Access to the olfactory mucosa was gained by removing the nasal bones and then by gently slipping aside the dorsal recess underlying them. Recordings were performed in the Endoturbinate at $0-400 \mu \mathrm{m}$ depth. Single-unit action potentials were recorded using metal-filled glass micropipettes $(2 \mu \mathrm{m}$ diameter, 3-7 $\mathrm{M} \Omega$ impedance at $1000 \mathrm{~Hz}$ ) and electro-olfactograms (EOGs) with glass micropipettes of $50 \mu \mathrm{m}$ diameter filled with saline solution gelled with agar. These signals were led through conventional amplifiers to a data tape recorder (Biologic, Claix, France) for off-line analysis.

Spike signals were filtered between 300 and $3000 \mathrm{~Hz}$. During experiments, the single-unit nature of the spikes was controlled by triggering the recorded cell on a memory oscilloscope. This allowed us to control the characteristics of the polyphasic spike of the recorded cell to ensure that the same cell was recorded during the entire experimental procedure.

Because recording a single ORN for a period long enough to test the 16 odorants used in this study was rather difficult, the presentation of the whole odor set was subdivided into three subsets. First, ACE, ANI, CAM, LIM, ISO, and MAK were systematically delivered. Then CDN, CIN, CYM, HEP, HEX, and VAN were presented. Last, $l$-CAR, $d$-CAR, $l$-CIT, and $d$-CIT were delivered when possible. Stimuli were delivered at random within each subset.

Data acquisition and response measurement. The single-unit activity and EOG signal were sampled off-line at $15 \mathrm{kHz}$ and $200 \mathrm{~Hz}$, respectively, using a CED-1401 data acquisition system (Cambridge Electronic Design, Cambridge, UK) connected to a computer. Spikes were first detected using their waveform as a criterion and then by verifying visually the consistency of the shapes of the sorted spikes on the computer screen. The stability and the unitary characteristics of the recordings were checked by following the form of the multiphase spikes and by selecting single-unit activities with a high signal-to-noise ratio.

EOG analysis consisted of measuring the latency and the peak amplitude of the signal with respect to the spontaneous baseline. The singleunit activity was processed to calculate the mean spontaneous firing frequency of the cell over a period of 3 min systematically sampled at the beginning of each recording and to determine its response type to each stimulus. Mean instantaneous frequencies of cells during their initial burst of response were calculated, and latencies of the first spike of this initial burst with respect to stimulation onset were measured.
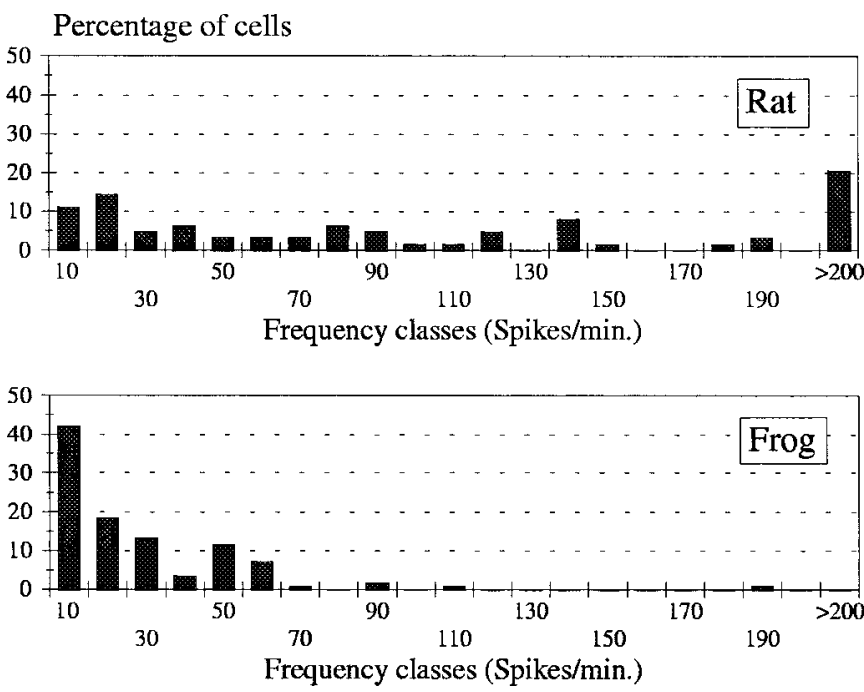

Figure 1. Distribution of spontaneous ORN firing frequencies in the rat $(n=90)$ and the frog $(n=99)$ (Revial et al., 1982).

\section{RESULTS}

The present analysis is based on the recordings of 90 ORNs that were performed in 19 freely breathing and 16 tracheotomized rats (Duchamp-Viret et al., 1999). Comparison was done with previous data gathered in the frog (Rana ridubunda) in our laboratory (Revial et al., 1982; Duchamp-Viret et al., 1989; 1990a,b; Duchamp-Viret and Duchamp, 1997).

\section{Spontaneous activity}

As shown in Figure 1, rat individual ORNs were generally more spontaneously active than frog ORNs. Indeed, only 2 of 124 cells recorded by Revial et al. (1982) in the frog had a spontaneous firing frequency between 100 and 200 spikes/min, and none fired at more than 200 spikes/min. In contrast, in the rat, $\sim 40 \%$ of the ORNs fired at more than 100 spikes/min. Nineteen cells fired at more than 200 spikes/min, and seven of them had a spontaneous firing frequency between 300 and 500 spikes/min.

\section{General odor responsiveness}

Figure 2 shows the single-unit activity of a rat ORN that was excited by 5 of the 10 odors tested and displayed different temporal response patterns and latencies. Such differences were similar to those described previously in the frog (Revial et al., 1982). Tonic long latency patterns were induced by ACE and LIM, whereas decremental and more frequency-sustained bursts were observed with ISO, ANI, and MAK.

In Figure 3, the percentages of excitatory and suppressive responses of rat ORNs to the six most frequently tested odors are compared with those elicited by the same odor series in the frog (Revial et al., 1982). The comparison between the two species was performed on responses to similar and high concentrations of each compound so that potential differences of sensitivity cannot interfere with results. Percentages of ORNs excited by the six stimuli were both high and very close in the two species. Percentages of suppressed ORNs were very low in the rat and nearly zero in the frog. Indeed, $1.8-10.7 \%$ of suppression was observed in the rat according to the odors, whereas only MAK and ACE induced 5.5 and $1.4 \%$ of suppressive responses, respectively, in the frog.

Figure 4 gives the probability of observing any combination of response types across the series of individual rat ORNs for the 


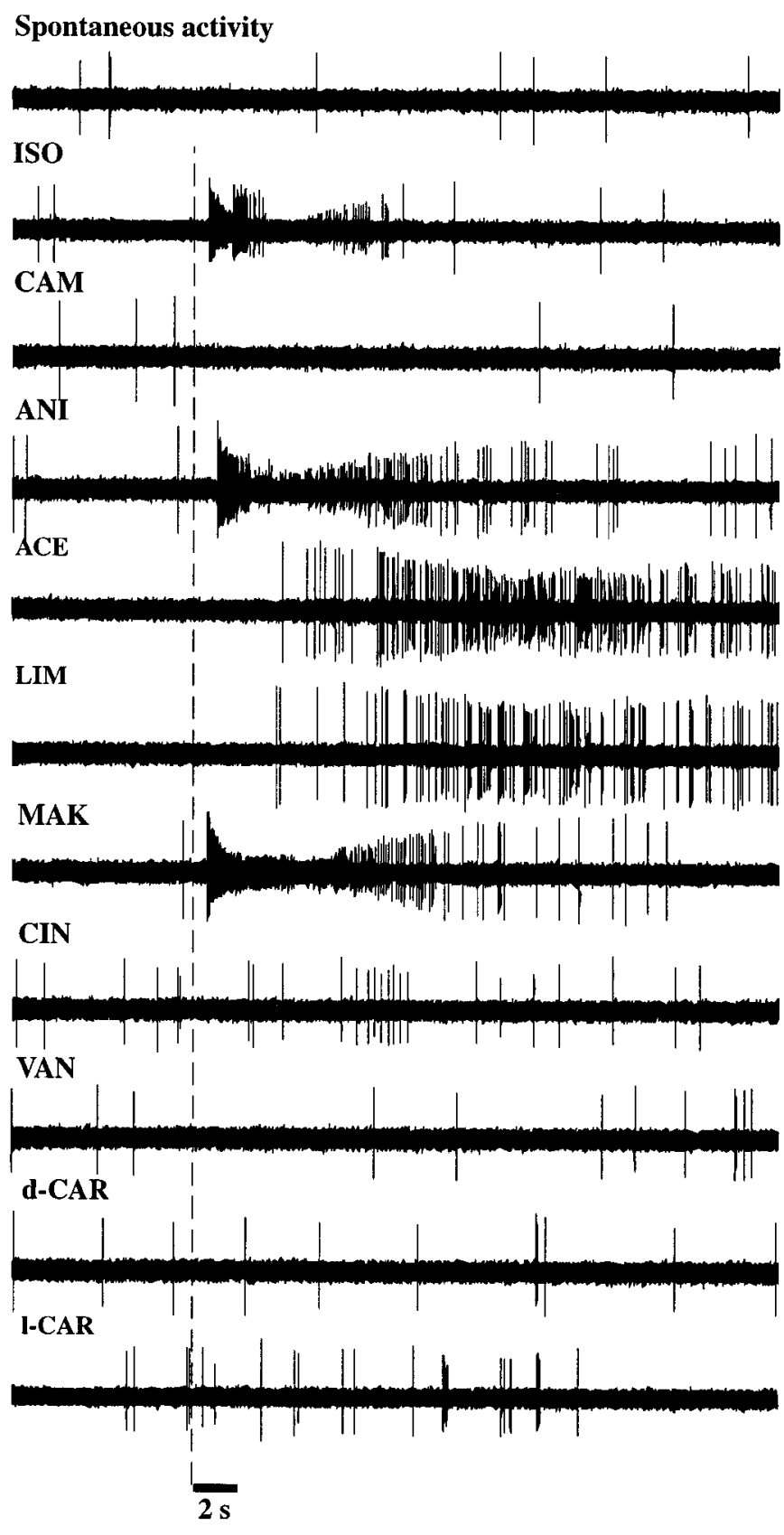

Figure 2. Spontaneous activity (top trace) and response profile (bottom traces) of ORN13 (raw data). This ORN was tested with all odors except CIT. It did not respond to CAM, CIN, VAN, $d$-CAR, and $l$-CAR, and to CYM, CDN, HEP, and HEX (data not shown). All its thresholds corresponded to SV/5.62, i.e., $3.5 \times 10^{-6} \mathrm{M} / 1$ for ACE, $1.9 \times 10^{-5} \mathrm{M} / 1$ for LIM, $3.5 \times 10^{-5} \mathrm{M} / 1$ for ANI and MAC, and $5.2 \times 10^{-5} \mathrm{M} / 1$ for ISO.

whole odor set or for the initial set of six odors. In this figure, the major response type was excitation ( $E$ and $E / N$ bars). Excitation and suppression were observed in the same ORN in $\sim 10 \%$ of the cells $(E / S$ and $E / S / N$ bars $)$.

\section{Selectivity and qualitative discrimination}

Four odors were commonly used at the same concentrations in this study and in a previous one in the frog (Duchamp-Viret, 1988). ORNs of the two species displayed different degrees of selectivity toward the four odors (Fig. 5). In the frog, most of the cells responded to one odor. Then, the proportion of excited cells
Percentages of responses

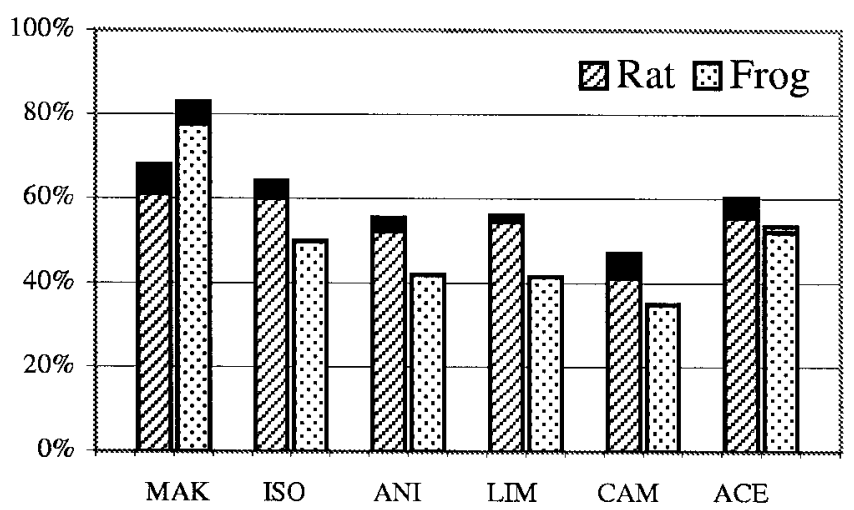

Figure 3. Percentages of excitatory (hatched and dotted bars) and suppressive (black bars) responses elicited by six odors commonly tested in the rat and frog.

\section{Percentage of cells}

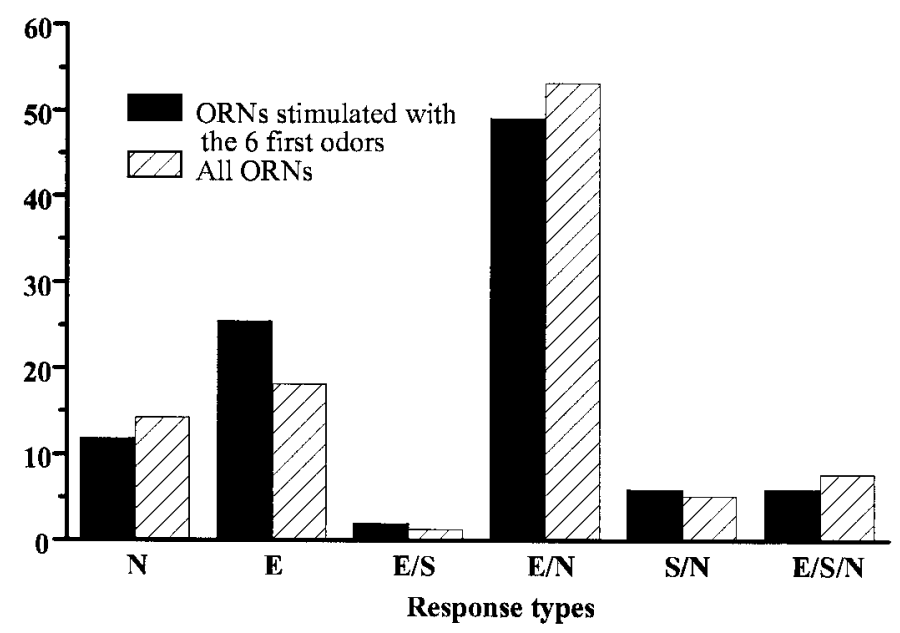

Figure 4. Distribution of response types in single ORNs response profiles. Black bars represent ORNs that were simulated with the six odors of the first subset (ACE, ANI, CAM, LIM, ISO, and MAC). Hatched bars represent ORNs that were tested with 2 of the 16 odors of our set. Bars represent response profiles of ORNs containing no response to all the tested odors $(N)$, excitatory responses only $(E)$, both excitatory and suppressive responses $(E / S)$, both excitatory and no responses $(E / N)$, both suppressive and no responses $(S / N)$, and excitatory, suppressive, and no responses $(E / S / N)$.

decreased when the number of stimuli was increased (DuchampViret et al., 1989). In contrast, in the rat, $\sim 32 \%$ of ORNs were found to be poorly selective because they responded to the four tested odors.

In the rat, the percentage of successful discrimination by odor pairs was determined for the whole odor set. We calculated the proportion of cells that responded to one odor with a response type and to another odor with a different response type or failed to respond, among the cells that responded at least to one of the two odors of the pair. Results are given in Figure 6 in which odor pairs were ranked according to their score of successful discrimination. Percentages of successful discrimination varied from 29 to $78 \%$. The least discriminated pair of odors was MAK-ISO, two linear ketones. The most well discriminated pairs were ISOCYM and ISO-CIN, i.e., a linear molecule (ISO) compared with 


\section{Percentage of cells}

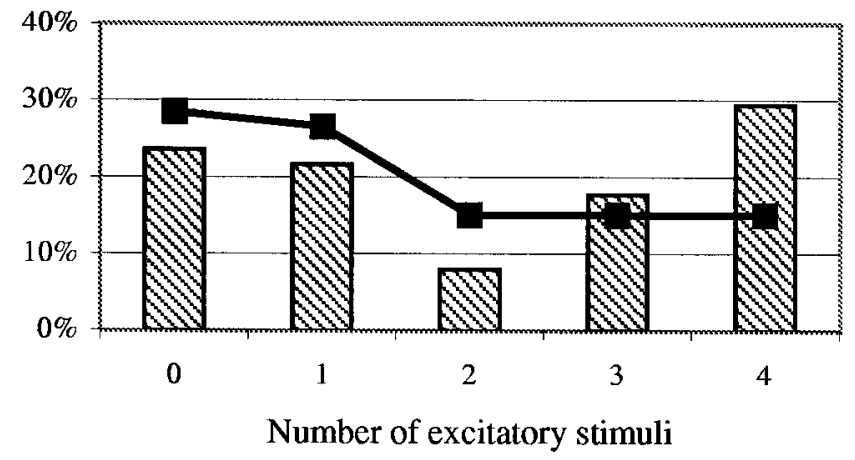

Figure 5. Selectivity of ORNs for ISO, LIM, ANI, and CAM. Distribution of the percentages of cells as a function of the number of odors to which they responded by excitation. Hatched bar, Rat $(n=51)$; line with symbols, frog $(n=60)$.

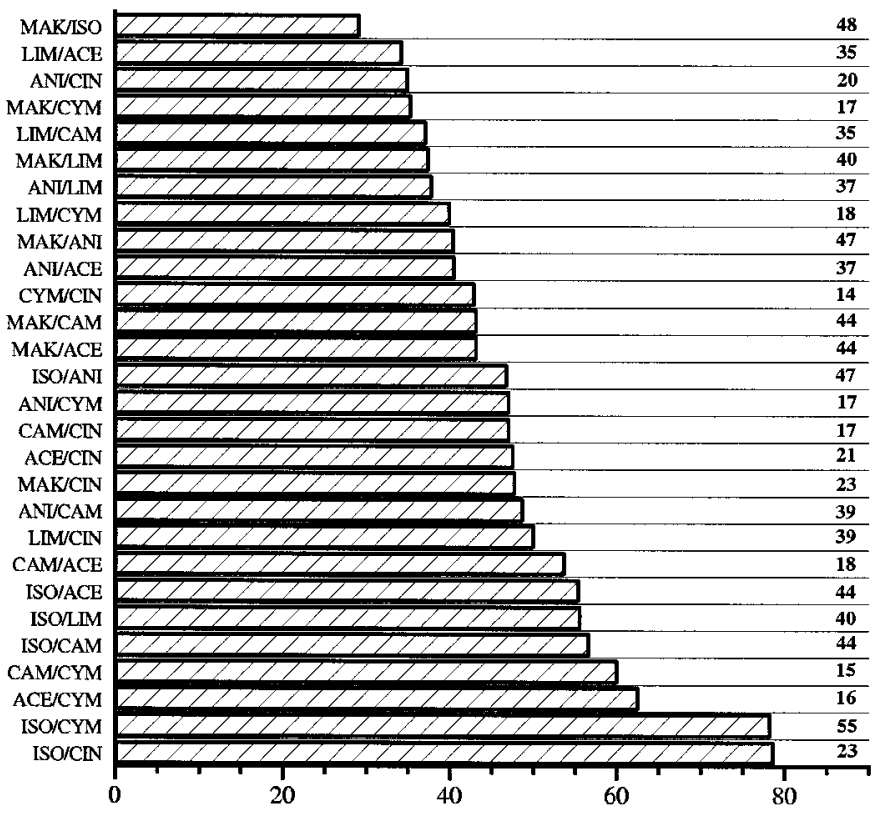

Percentages of qualitative discrimination

Figure 6. Percentages of successful discrimination of odor pairs by rat ORNs. On the right are indicated the number of pairs used for each comparison. Only pairs presented to at least 15 cells are shown.

a terpene (CYM) or with a small round camphoraceous molecule (CIN). The less well discriminated odor pairs corresponded to those linked by the $\chi^{2}$ computation. A principal component analysis was applied to the responses to the six most frequently tested odors (data not shown). It grouped the two linear molecules (ISO and MAK) on the one hand and the two aromatic compounds (ACE and ANI) on the other hand. These two groups were separated from the terpene (LIM) and the camphoraceous compound (CAM). These results are similar to those described in the frog (Sicard and Holley, 1984).

Based on the four odors commonly used in the frog and rat at the same concentrations, it was possible to compare the percentages of successful discrimination of odor pairs in the two species (rat, $n=51$; frog, $n=60$ ). As seen in Figure 7, the discrimination abilities of ORNs were not statistically different in the rat and frog (nonparametric Kruskal-Wallis test).
Successful discrimination of pairs

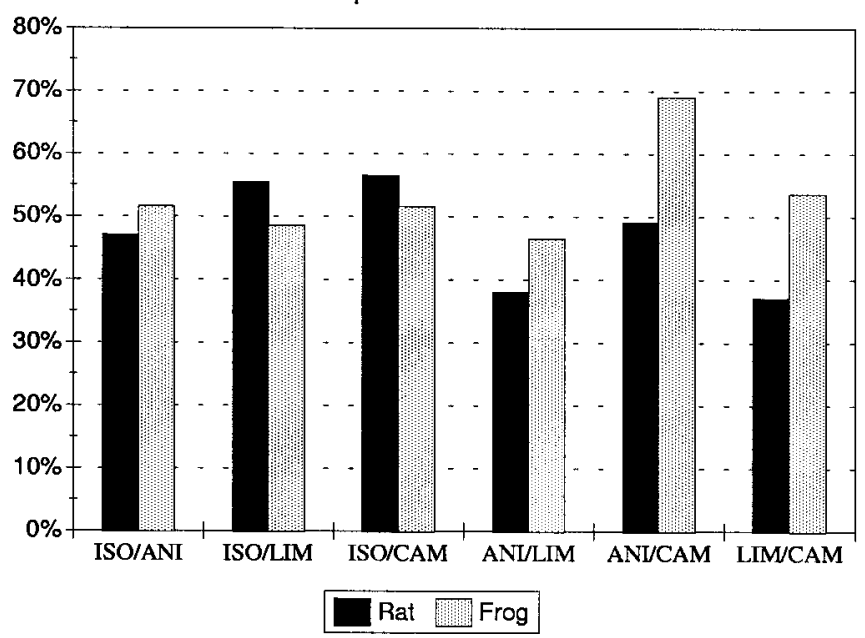

Figure 7. Percentages of successful discrimination of odor pairs in the rat and frog for ANI, ISO, LIM, and MAK.

\section{Intensity coding}

In the rat, 21 cells were studied with concentration series. Over these cells, the evolution of excitatory responses with concentrations was rather similar. Stimulus strength was obviously transduced into firing increases. Near thresholds, ORNs gave tonic response patterns. When increasing concentrations, frequency generally increased, and burst duration and latency decreased. However, even at high concentrations, some cells that responded with high-frequency bursts still discharged with a long latency (Fig. 2). Actually, latencies of rat ORNs ranged from $200 \mathrm{msec}$ to several seconds as described previously in the frog (Revial et al., 1982; Duchamp-Viret et al., 1990b). Concentration-response series are illustrated through responses of ORN50 in Figure 8, and the high-frequency bursts constituting the initial sustained excitatory responses of this cell are shown in Figure 9. For high concentrations, this cell gave early regular and rhythmic decremental bursts. Discharge frequencies were very high, and the size of the spikes were assumed to be reduced proportionally to the amplitude of the odor-evoked depolarization as described previously through intracellular recordings in the salamander (Trotier and Mac Leod, 1983) and extracellular recordings in the frog (Revial et al., 1982). When repolarizing, ORNs gave incremental discharges that constituted "off" effects of the initial responses. By pooling the discharges of the population of ORNs, such delayed off discharges were shown previously not to prevail in the overall output activity flow rate of the mucosa (Duchamp-Viret et al., 1990).

Using such temporal response series, concentration-discharge frequency curves and corresponding concentration-latency curves were established. Although the aspect of frequency curves directly depends on the method of quantification, they give a synthetic view of spike frequency odor coding. As with frog ORNs, rat ORNs never adapted in our experimental conditions. Moreover, they showed reproducible responses to repeated presentations of the same stimulus, as exemplified by the two traces at the bottom of Fig. 9. Concentration-response curves established for rat ORN50 (whose response patterns were shown in Fig. 8) and ORN55 are given in Figures 10 and 11, respectively. These examples well illustrate how the frequency of the spike discharge and the amplitude of the EOG recorded simultaneously increased 
Spontaneous activity

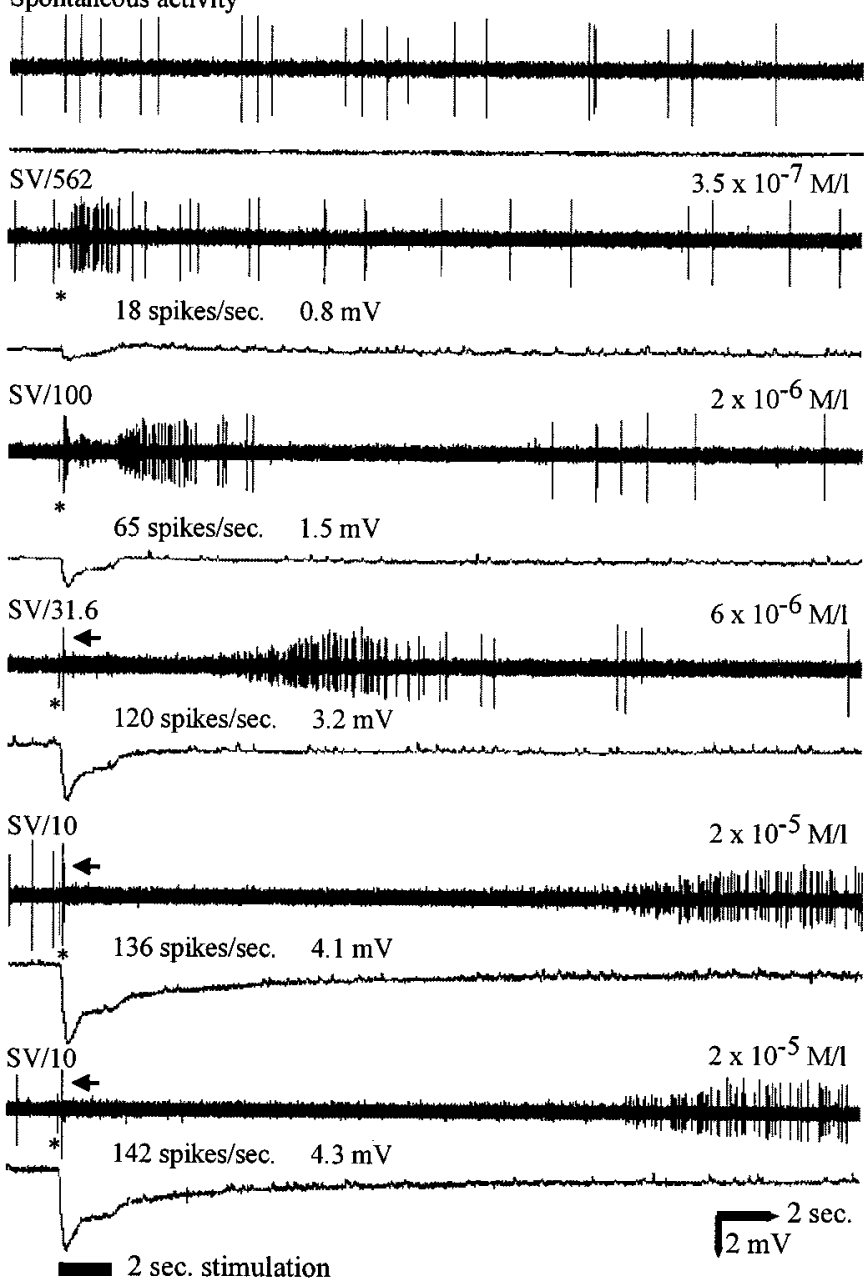

Figure 8. Spontaneous (top trace) and odor-evoked single-unit responses and EOGs (pairs of bottom traces) of rat ORN50 (raw data) to increasing concentrations of ANI. Recordings obtained for two presentations at $1.98 \times 10^{-5} \mathrm{M} / 1(\mathrm{SV} / 10)$ illustrate the reproducibility of the response. Firing frequencies in the initial response burst and amplitudes of the EOG are given between the respective recordings. Concentrations (molar) are on the left and right, respectively. Asterisks below single-unit recordings indicate the artifact at the beginning of the stimulation. This ORN had a mean spontaneous firing frequency of $\sim 1$ spike/sec.

with concentration. Moreover, the insets in Figures 10 and 11 show how the latencies of the spike bursts and EOG responses decreased with concentrations. More precisely, Figure 10 shows that ORN50 responded from the lowest concentration but with a latency of $500 \mathrm{msec}$. Thus, at low concentrations, this cell did not participate to the genesis of the early phase of EOG. When concentrations increased, response latency decreased to the EOG latency. This would result in a synchronization of the population of ORNs at high concentration as described previously in the frog (Duchamp-Viret et al., 1990b). ORN55 (Fig. 11) reached its threshold, whereas the EOG response was detectable at lower concentrations. Moreover, its latency was high ( $>1 \mathrm{sec})$. At higher concentrations, the beginning of the cell discharge and EOG were simultaneous. Very similar types of concentration-response relationships were observed in the frog (Duchamp-Viret, 1988). Nevertheless, rat ORNs were able to fire at very high frequencies, up to 142 spikes/sec, compared with frog ORNs, which reached a maximum rate of $\sim 60 \mathrm{spikes} / \mathrm{sec}$.

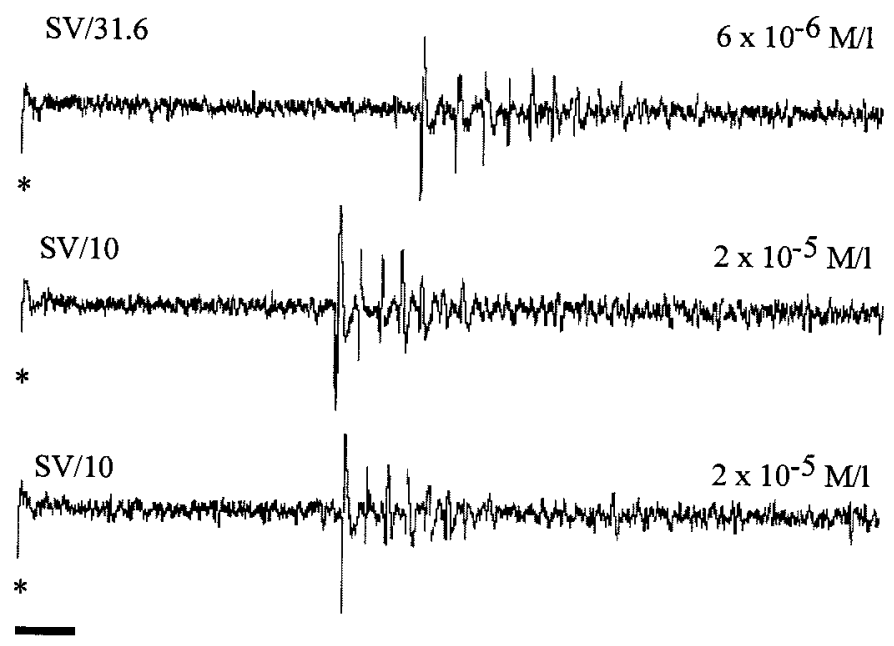

$20 \mathrm{msec}$.

Figure 9. Detail of Figure 8. Initial decremental response bursts of ORN50 (indicated by arrowheads in Fig. 8) elicited at high concentrations.

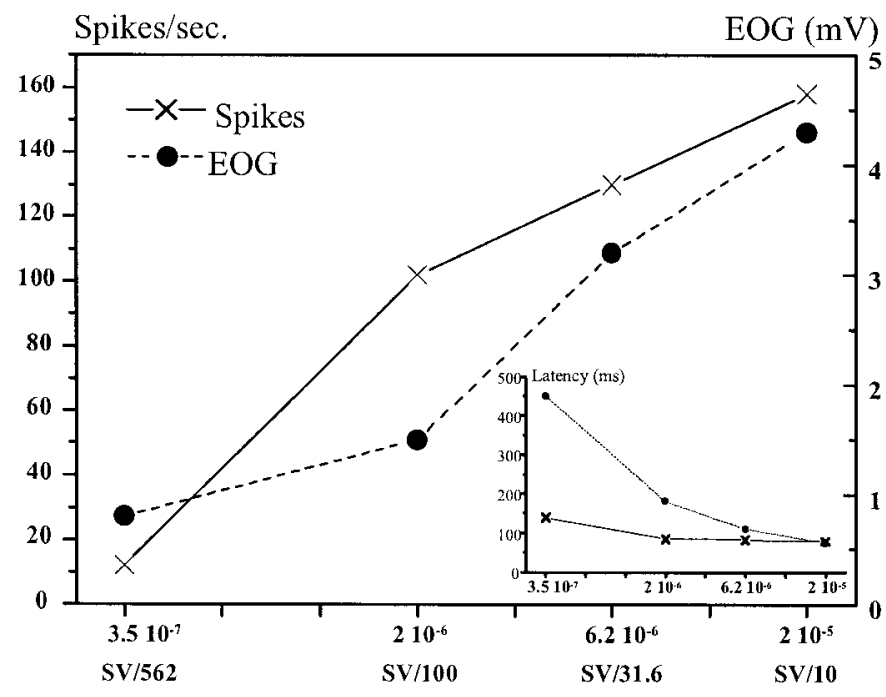

Concentrations of ANI in M/l and in fraction of SV

Figure 10. Concentration-response curves of ORN50 spike frequency and EOG amplitude, and their corresponding latency curves (inset).

\section{The sensitivity of the ORN}

In the rat, 55 response thresholds were determined for 21 of 51 cells systematically stimulated with the six odorants. Figure 12 presents their distribution as a function of the stimulus concentration expressed in terms of number of odor molecules per liter. For each odorant, thresholds were distributed on the whole concentration range used in the study but showed a tendency to gather toward the lowest and highest concentrations.

Figure 13 shows the recruitment of the rat ORNs for the four odors tested communally in the rat and frog (Duchamp-Viret et al., 1989). It gives for the four odors together the cumulated proportion of cells in which response thresholds were reached or surpassed as a function of increasing concentration. Both frog and rat recruitment curves have approximately the same shape, but in the frog, the curve is shifted toward the lower concentrations. Approximately $50 \%$ of the frog ORNs were recruited at 


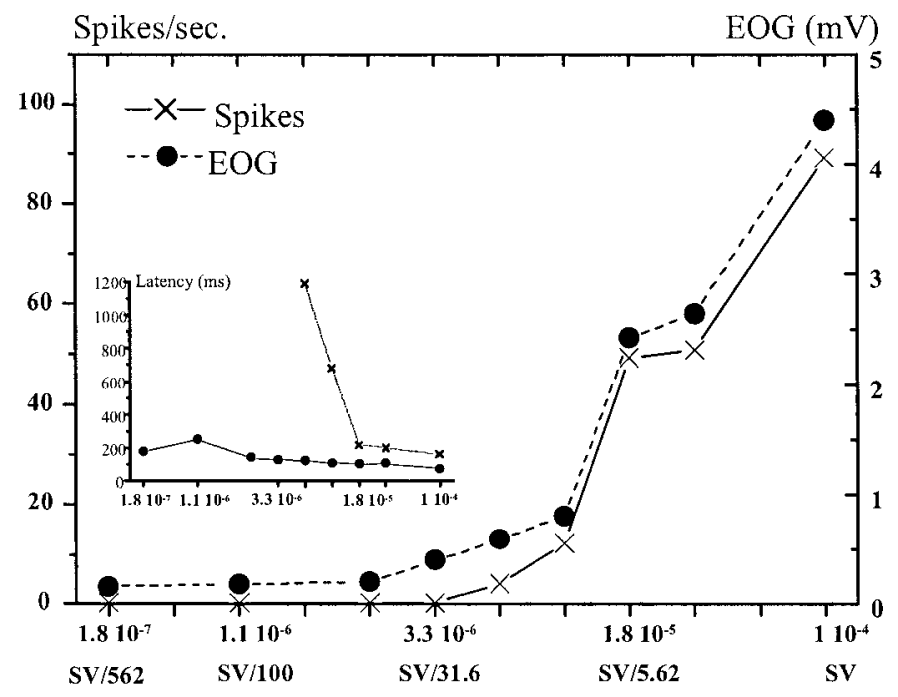

Concentrations of LIM in M/1 and in fraction of SV

Figure 11. Concentration-response curves of ORN55 spike frequency and EOG amplitude, and their corresponding latency curves (inset).

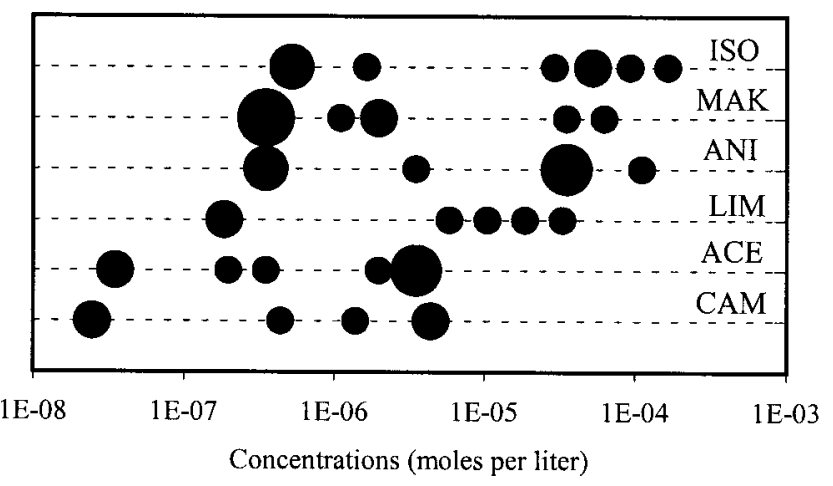

Figure 12. Distribution of rat ORNs response thresholds $(n=55)$ over the concentrations ranges for the six odors of the first subset. For each odor, the diameters of the filled circles are proportional to the number of thresholds determined for a given concentration.

$1 / 2000$ of saturated vapor, whereas $50 \%$ of the rat ORNs were recruited at $1 / 20$ of saturated vapor. The lower number of active ORNs at low concentration in the rat may be the sign of a lower sensitivity or a higher selectivity of the cell population for these tested odors.

\section{DISCUSSION}

This comparison of response properties of ORNs in the rat and the frog was not planed to focus on interspecies similarities or differences per se but rather to draw general principles of the functioning of the vertebrates' olfactory system using these two animal species as a model. On the whole, rat and frog ORNs were found to function similarly. The small differences observed are discussed below.

In the rat, the observation of suppressive responses was facilitated by the relatively high rates of spontaneous firing of ORNs. However, the number of suppressive responses was low but higher than in the frog in which suppressive responses were rarely observed (Revial et al., 1978a,b, 1982, 1983). In terrestrial vertebrates, the $\mathrm{IP}_{3}$ transduction pathway was reported to be at the

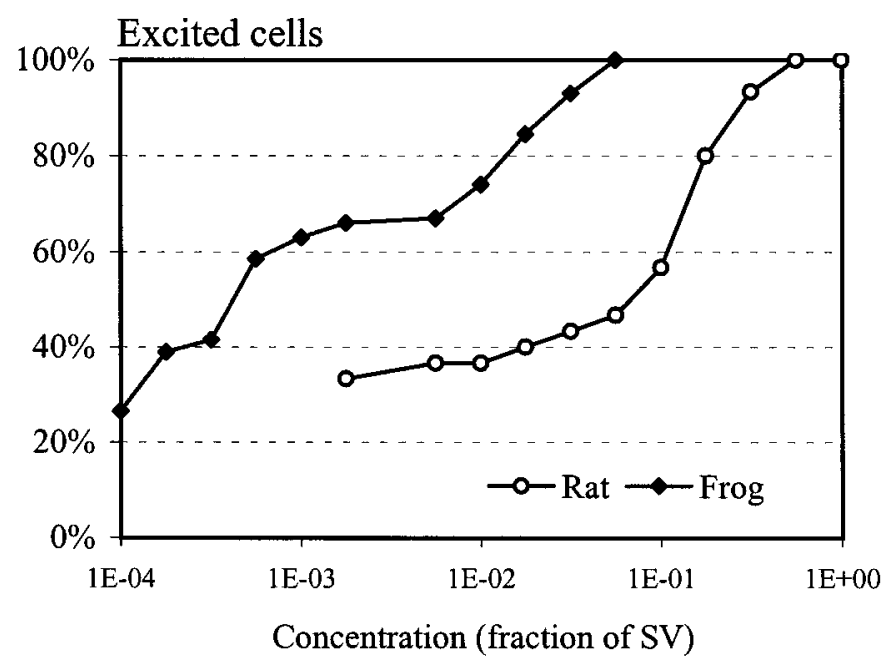

Figure 13. Dynamics of ORNs recruitment for ANI, CAM, ISO, and LIM in the rat and frog. The cumulative number of excited cells is represented as a function of concentration. One hundred percent of excited cells correspond to 53.5 and $59 \%$ of the total number of stimulation performed in the rat and frog, respectively. We had observed in preliminary experiments the low sensitivity of rat ORNs compared with the frog. This led us to shift the concentration range available toward higher values. Thus, concentrations lower than SV/1000 were not tested in the rat.

origin of suppressive responses, whereas the cAMP transduction pathway would generate excitatory responses, with these two transduction pathways being the targets for distinct odor molecules (Sklar et al., 1986; Raming et al., 1993). In agreement with the literature, the few inhibitory responses observed in the present study were assumed to be attributable to the fact that the used odor stimuli were mainly devoted to set in motion the cAMP pathway.

Another explanation would be that suppressive responses could result from interactions between several molecules composing a mixture at the level of the two transduction pathways. Thus, the low number of suppressive responses observed in the present experiment may result from the use of pure chemicals. In contrast, when ORNs are stimulated with an odor mixture, the probability of activating the two transduction pathways (cAMP and $\mathrm{IP}_{3}$ ) would be increased. This is all the more probable that the existence of these two pathways has been evidenced in the two species (Sklar et al., 1986; Breer et al., 1990) and that a single ORN would be endowed with the two pathways (Dionne, 1992; Miyamoto et al., 1992; Ngai et al., 1993; Kang and Caprio, 1995a,b; Cromarty and Derby, 1997; Sanhueza and Bacigalupo, 1999).

Although to date the question of the genesis of excitatory or suppressive responses through $\mathrm{cAMP}$ and $\mathrm{IP}_{3}$ pathways has not been elucidated in vertebrates, some observations done in the frog are in favor of the hypothesis that the expression of inhibitory mechanisms in vertebrate ORNs could result from odor molecular interactions (Revial et al., 1978). For example, a mixture of cineole and anethole has been shown to induce a weaker response than the latter odorant alone, and an excitatory response to cineole has been shown to become a suppressive response when the application of this odorant was preceded by the delivery of anisole, bromobenzene, dichlorobenzene, or anethole, all molecules that belong to the aromatic group (Duchamp-Viret and Duchamp, 1997). Moreover, some authors have shown that 
ORNs for which one component of a binary mixture is excitatory and the second is either neutral or inhibitory commonly can show mixture suppression (Derby et al., 1989; Michel and Ache, 1992, 1994; Daniel et al., 1994, 1996; Kang and Caprio, 1997). Such phenomena have been named mixture interactions (Laing et al., 1984). Given these data, the present observation that only $10 \%$ of rat ORNs were excited by a stimulus and inhibited by another (Fig. 4) could be explained by the lack of molecular interactions when pure chemicals are used and by the fact that our odor set was small compared with all potential odors. We assume that the effectiveness of stimuli of inducing excitatory responses was maximal in our experimental conditions, as well as in frog studies, in which ORNs worked within a frame devoid of molecular interactions at the level of the ORs. This may also account for the only $15-20 \%$ of ORNs that did not respond to any stimulus in the rat and frog, respectively.

In contrast, the use of pure chemicals may have a detrimental effect on the mechanisms of qualitative discrimination because it can be easily imagined that the overlapping of arrays of excited ORNs that coded for different stimuli ought to be greater without molecular competition than in odor mixtures. However, despite this assumption, up to $80 \%$ discrimination was observed for some odor pairs (Fig. 6). In the rat, the possibility of a large overlap of arrays of ORNs, especially represented by the $30 \%$ of neurons that responded to the six most frequently tested odors, i.e., that were not selective (Duchamp-Viret et al., 1999, their Table 1), implies that molecular receptors borne by single ORNs would be capable of recognizing several distinct molecular structures and conversely that a given molecule would bind with several molecular receptors. This is in agreement with the recent results of Malnic et al. (1999).

If the selectivity of ORNs directly mirrors the specificity of ORs, the $30 \%$ of ORNs that were not selective to the six most frequently tested odors in the rat may signify that peripheral abilities to discriminate the stimuli are reduced in the rat with respect to the frog. However, the comparison of the percentages of discrimination of the odor pairs used in both species did not show such a decrease (Fig. 7). Here, as in previous studies (for review, see Duchamp-Viret and Duchamp, 1997), the ability of ORNs to discriminate odors was estimated to be directly proportional to their selectivity. However, even nonselective ORNs may be envisaged as discriminating two odors if these odors elicit two distinct temporal response patterns. In the first stage of the olfactory system, the "rate coding mode" is widely accepted, and the high convergence of the projections of the ORNs on bulbar glomeruli seems not favorable to the preservation of a "time coding mode". Further studies would be necessary to precisely analyze spike trains of ORNs and to shed light on this question more definitively.

To really compare the selectivity of and discrimination abilities of ORNs in these two vertebrate species, the relevance of stimulus concentration and its interaction with selectivity must be taken into account. In the rat, we show that the number of responding ORNs increases with concentration (Fig. 13). This is in agreement with the literature on the rat (Sato et al., 1994; Malnic et al., 1999) and has been shown previously in the frog (Duchamp-Viret et al., 1989). Assuming that this fact mirrors, at least partly and indirectly the specificity of ORs, this seems to signify that this specificity would decrease when concentration increases. However, this result can be interpreted differently, especially in the rat because response thresholds of ORNs, although distributed over all the available concentration range, tended to be more numerous at the two extremes of this range. This may reveal two different functioning modes of the olfactory system.

A first mode of functioning of the ORNs would be concerned with low and medium concentrations and would involve only highly specific binding mechanisms. Here, ORNs would be highly selective, thus implying that the probability to find their specific ligand is very low by using a small number of stimuli. In the rat, the especially low percentage of involved ORNs in the coding of an odorant would be compensated first by a higher number of ORNs, $32 \times 10^{6}$ ORNs per mucosa (Meisami, 1991) against $2-5 \times 10^{6}$ in the frog (Bronstein, 1977), and second by a glomerular convergence ratio $\sim 24$-fold higher in the rat (Meisami, 1991) than in the frog (Byrd and Burd, 1991). Thus, at low concentration, the sensitivity of the system would be preserved in the rat, despite a higher selectivity of ORNs. More generally in vertebrates, odor quality would be encoded at low concentrations by arrays of ORNs that have little overlap in response, with their overlap increasing with concentration. The effectiveness of stimuli is assumed to be maximal in our experimental conditions, and this overlap would be limited with natural odor or mixtures, thanks to molecular interactions between components or competition at binding site levels and to the duality of the transduction pathways. Thus, a mixture would have its own unique quality that may arise from these mechanisms (Derby et al., 1989; Daniel et al., 1996).

A second mode of ORNs functioning would concern high concentrations in which less specific mechanisms would occur involving olfactory receptors with lower affinities. In the present experiment, this mode of functioning was especially evident because the use of pure chemicals avoided the interactions between different molecules, whereas such interactions would favor high affinity binding. In contrast with natural odors or experimental mixtures, our opinion is that this less specific binding of odor molecules on receptor sites would be all the more limited than mixtures are complex.

Our results show that intensity coding seems to be ensured through an increase of the discharge frequency in initial bursts that occurs earlier with concentration. Moreover, the number of recruited ORNs increases with concentration. Such a cell recruitment process implies that the combination of ORNs stimulated by an odorant will progressively be enriched with intensity. Such a progressive change in combinations of ORNs as a function of concentration may have a consequence on the odor qualitative identity. As a matter of fact, combinations of ORNs elicited by a low and a high concentration of the same odorant might be analyzed as distinct qualities. However, we propose that this does not imply that odor quality shifts systematically with concentration because the recruitment process has been described previously as useful to specify the odor quality feature of the combinations of ORNs in the frog (Duchamp-Viret et al., 1989, 1990a; Sato et al., 1994; Malnic et al., 1999). An alternative hypothesis is that the identity of recruited ORNs with concentration would specify not only the quality of an odor but also its intensity (Duchamp-Viret, 1988; Derby et al., 1991).

In conclusion, airborne olfactory reception could be ensured over terrestrial life vertebrates through very universal mechanisms. From amphibians to mammals, phylogenetic evolution likely accounts for an increase of specificity of ORs. Nevertheless, the combinatorial-coding mode remains valid because it is unrestrictive. From a perceptual and behavioral point of view, this latter property appears all the more useful because vertebrates 
were confronted with a larger number of odor molecules when they acceded to a terrestrial life. During this kind of adaptation, the olfactory system had to increase the specificity of ORs while preserving the multiplicity of coding possibilities.

\section{REFERENCES}

Breer H, Boekhoff I, Tareilus E (1990) Rapid kinetics of second messenger formation in olfactory transduction. Nature 345:65-68.

Bronstein AA (1977) Olfactory receptors of vertebrates (in Russian) (Setchenova IM, ed), pp 1-159. Leningrad: Sciences Editions.

Buck L (1993) Identification and analysis of a multigene family encoding odorant receptors: implications for mechanisms underlying olfactory information processing. Chem Senses 18:203-208.

Buck L, Axel R (1991) A novel multigene family may encode odorant receptors: a molecular basis for odor recognition. Cell 65:175-187.

Byrd CA, Burd GD (1991) Development of the olfactory bulb in the clawed frog, Xenopus laevis: a morphological and quantitative analysis. J Comp Neurol 314:79-90.

Cromarty SI, Derby CD (1997) Multiple excitatory receptor types on individual olfactory neurons: implications for coding of mixtures in the spiny lobster. J Comp Physiol [A] 180:481-491.

Daniel PC, Fine JB, Derby CD, Girardot MN (1994) Non-reciprocal cross-adaptation of spiking responses of individual olfactory receptor neurons of spiny lobsters: evidence for two excitatory transduction pathways. Brain Res 643:136-149.

Daniel PC, Burgess MF, Derby CD (1996) Responses of olfactory receptor neurons in the spiny lobster to binary mixtures are predictable using a non-competitive model that incorporates excitatory and inhibitory transduction pathways. J Comp Physiol [A] 178:523-536.

Derby CD, Girardot MN, Daniel PC, Fine-Levy JB (1989) Olfactory discrimination of mixtures: behavioral, electrophysiological and theoretical studies using the spiny lobster Panulirus argus. In: Perception of complex smells and tastes (Laing DG, Cain WS, McBride RL, Ache BW, eds), pp 65-81. Sydney: Academic.

Derby CD, Girardot MN, Daniel PC (1991) Responses of olfactory receptor cells of spiny lobsters to binary mixtures. II. Pattern mixture interactions. J Neurophysiol 66:131-139.

Dionne VE (1992) Chemosensory responses in isolated olfactory receptor neurons from Necturus maculosus. J Gen Physiol 99:415-433.

Duchamp A, Revial MF, Holley A, Mac Leod P (1974) Odor discrimination by frog olfactory receptors. Chem Senses 1:213-233.

Duchamp-Viret P (1988) Le codage intensitif du stimulus olfactif: rôle des neurorécepteurs et de deutoneurones, étude électrophysiologique chez la grenouille. PhD thesis, Claude Bernard University, Lyon I.

Duchamp-Viret P, Duchamp A (1997) Odor processing in the frog olfactory system. Prog Neurobiol 53:561-602.

Duchamp-Viret P, Duchamp A, Vigouroux M (1989) Amplifying role of convergence in olfactory system. A comparative study of receptor cell and second order neuron sensitivities. J Neurophysiol 61:1085-1094.

Duchamp-Viret P, Duchamp A, Sicard G (1990a) Olfactory discrimination over a wide concentration range. Comparison of receptor cell and bulb neuron abilities. Brain Res 517:256-262.

Duchamp-Viret P, Duchamp A, Vigouroux M (1990b) Temporal aspects of information processing in the first two stages of the frog olfactory system: influence of stimulus intensity. Chem Senses 15:349-365.

Duchamp-Viret P, Chaput MA, Duchamp A (1999) Odor response properties of rat olfactory receptor neurons. Science 284:2171-2174.

Erickson RP (1963) Sensory neural patterns and gustation. In: Olfaction and taste I (Zotterman Y, ed), pp 205-213. New York: MacMillan.
Kang JS, Caprio J (1995a) Electrophysiological responses of single olfactory bulb neurons to amino acids in the channel catfish, Ictalurus punctatus. J Neurophysiol 74:1421-1434.

Kang JS, Caprio J (1995b) Electrophysiological responses of single olfactory bulb neurons to binary mixtures of amino acids in the channel catfish, Ictalurus punctatus. J Neurophysiol 74:1435-1443.

Kang JS, Caprio J (1997) In vivo responses of single olfactory receptor neurons of channel catfish to binary mixtures of amino acids. J Neurophysiol 77:1-8.

Laing DG, Panhuber H, Willcox ME, Pittman EA (1984) Quality and intensity of binary odor mixtures. Physiol Behav 33:309-314.

Malnic B, Hirono J, Sato T, Buck LB (1999) Combinatorial receptor codes for odors. Cell 96:713-723.

Meisami E (1991) Chemoreception. In: Neural and integrative animal physiology, Vol 2, Comparative animal physiology, Ed 3 (Ladd Prosser C, ed), pp 335-434. New York: Wiley.

Michel WC, Ache BW (1992) Cyclic nucleotides mediate an odorevoked potassium conductance in lobster receptor cells. J Neurosci 12:3979-3984.

Michel WC, Ache BW (1994) Odor-evoked inhibition in primary olfactory receptor neurons. Chem Senses 19:11-24.

Miyamoto T, Restrepo D, Cragoe EJ, Teeter JH (1992) IP $_{3}$-induced and cAMP-induced responses in isolated olfactory receptor neurons from the channel catfish. J Membr Biol 127:173-183.

Ngai J, Chess A, Dowling M, Maxel R (1993) Expression of odorant receptor genes in the catfish olfactory epithelium. Chem Senses 18:209-216.

Raming K, Krieger J, Strotmann J, Boekhoff I, Kubick S, Baumstark C, Breer H (1993) Cloning and expression of odorant receptors. Nature 361:353-356.

Revial MF, Duchamp A, Holley A (1978a) Odour discrimination by frog olfactory receptors: a second study. Chem Senses 3:7-21.

Revial MF, Duchamp A, Holley A, Mac-Leod P (1978b) Frog olfaction: odour groups acceptor distribution and receptor categories. Chem Senses 3:23-33.

Revial MF, Sicard G, Duchamp A, Holley A (1982) New studies on odour discrimination in the frog's olfactory receptor cells. I. Experimental results. Chem Senses 7:175-190.

Revial MF, Sicard G, Duchamp A, Holley A (1983) New studies on odour discrimination in the frog's olfactory receptor cells. II. Mathematical analysis of electrophysiological responses. Chem Senses 8:179-194.

Sanhueza M, Bacigalupo J (1999) Odor suppression of voltage-gated currents contributes to the odor-induced response in olfactory neurons. Am J Physiol 277:C1086-C1099.

Sato T, Hirono J, Tonoike M, Takebayashi M (1994) Tuning specificities to aliphatic odorants in mouse olfactory receptor neurons and their local distribution. J Neurophysiol 72:2980-2989.

Sicard G, Holley A (1984) Receptor cell responses to odorants: similarities and differences among odorants. Brain Res 292:283-296.

Sklar PB, Anholt RRH, Snyder SH (1986) The odorant-sensitive adenylate cyclase of olfactory receptor cells. J Biol Chem 261:15538-15543.

Trotier D, Mac Leod P (1983) Intracellular recordings from salamander olfactory receptor cells. Brain Res 268:225-237.

Vigouroux M, Viret P, Duchamp A (1988) A wide concentration range olfactometer for delivery of short reproducible odor pulses. J Neurosci Methods 24:57-63. 